\title{
Normal Ocular Protrusion Values in South Indian Population and Effect of Age, Gender and Refractive Status on Ocular Protrusion
}

This article was published in the following Dove Press journal: Clinical Ophthalmology

\author{
Naveen Kumar Challa ${ }^{1,2}$ \\ Waleed M Alghamdi ${ }^{1}$ \\ 'Department of Optometry, College of \\ Applied Medical Sciences, Qassim \\ University, Buraidah, Saudi Arabia; ${ }^{2}$ Lotus \\ Eye Care Hospital, Coimbatore, India
}

Aim: To determine the absolute and relative ocular protrusion values in normal south Indian population, and its relation to age, gender and type of refractive error.

Methods: A total of 387 subjects aged 7-70 years were included in this study. Both right and left absolute ocular protrusion values were measured by a single physician using Luedde exophthalmometer in primary gaze. Right eye ocular protrusion data were used for reporting the absolute ocular protrusion values, and difference between right and left eye absolute ocular protrusion values of the same individual was used to report the relative ocular protrusion values. Subject age was grouped as decades. Measurement values were evaluated by descriptive and inferential statistics.

Results: The mean absolute ocular protrusion of right eye was $14.67 \pm 1.70 \mathrm{~mm}$ and left eye was $14.32 \pm 1.75 \mathrm{~mm}$. The mean right absolute ocular protrusion values from 1 st to 7 th decade were $12.73 \pm 1.21 \mathrm{~mm}, 14.8 \pm 1.25 \mathrm{~mm}, 15.79 \pm 1.31 \mathrm{~mm}, 15.77 \pm 1.36 \mathrm{~mm}, 15.87 \pm$ $1.28 \mathrm{~mm}, 15 \pm 1.03 \mathrm{~mm}$ and $14.36 \pm 0.88 \mathrm{~mm}$ respectively. One-way analysis of variance showed that there was a significant difference in the ocular protrusion among the age groups $(p<0.005)$. The mean relative ocular protrusion was $0.35 \pm 0.64 \mathrm{~mm}$. The type of refractive error (up to $\pm 6.00 \mathrm{D}$ ) has no significant effect on the absolute ocular protrusion values and showed a weak correlation between magnitude of myopia and hyperopia on absolute ocular protrusion. There was a statistically significant difference in absolute ocular protrusion among the female and male subjects.

Conclusion: Age and gender seems to significantly influence the absolute ocular protrusion and need to be considered for clinical evaluation of bilateral proptosis. The refractive error up to $\pm 6.00 \mathrm{D}$ seems to have no significant effect on the absolute ocular protrusion.

Keywords: absolute, relative, ocular protrusion, exophthalmometer, refractive status, proptosis

\section{Introduction}

The orbit is an osseous pyramid and contains orbital soft tissues and the eyeball. It is a rigid box whose contents can be expanded only anteriorly. Therefore, any increase in intraorbital volume results in anterior displacement of the eye, a condition known as ocular proptosis. The increase in ocular protrusion is an important clinical sign in orbital disease. ${ }^{1}$

Measurement of ocular protrusion is a routine diagnostic test for cases of suspected orbital disease. Ocular protrusion values help to diagnose orbital disease, and serial measurements would help in monitoring the progression of the same. ${ }^{2}$
Correspondence: Naveen Kumar Challa Qassim University, P.O. Box: II62, Buraidah, Saudi Arabia

Tel +966531177518

$\mathrm{Fax}+966(16) 3800050$

Email N.challa@qu.edu.sa 
Ocular protrusion can be measured simply using exophthalmometers or using sophisticated radiology techniques such as MRI and CT scan. Though these sophisticated techniques are accurate in measurement, they are very expensive and not suitable for epidemiological studies involving large samples. Moreover, CT scan can lead to long exposure to radiation. ${ }^{3-5}$ Considering the ease of use and portability of exophthalmometers, they are widely used in ophthalmology clinics. Three types of exophthalmometers that are commonly used in the clinics are Hertel, Luedde and Naugle. The first two would measure the absolute ocular protrusion, while the third one would measure the relative ocular protrusion. ${ }^{6}$ Absolute ocular protrusion is measured and compared to a standard average value, and it is an important procedure in the diagnosis of bilateral proptosis, in which the protrusion of the two eyes is equal. The relative ocular protrusion is the protrusion of an eye compared with the other eye of the same individual. It is very important in the diagnosis of unilateral proptosis. $^{7-9}$

As per the current literature, there is wide diversity, and range exists in ocular proptosis values among the different populations. So it becomes important to consider the normative data of ocular protrusion in specific groups of populations while evaluating the results of measurements. However, there are no studies that measured the normative ocular protrusion values in south India. Considering the importance of establishing normative data in south Indian population, this study aimed to measure the absolute and relative ocular protrusion values in south Indian population. Additionally, studies have provided conflicting views regarding association between age and gender on ocular protrusion. ${ }^{2,3,10}$ So the present study aimed to see the relationship between age and ocular protrusion to enhance the debate between previously reported studies. Furthermore, we explored the effect of refractive status and gender on ocular protrusion.

\section{Methods and Materials}

A total of 387 subjects aged between 7 and 70 years presenting to either the outpatient department of Lotus Eye Care Hospital and Institute or camps conducted by Lotus Eye Care Hospital and Institute in the Coimbatore region, India, with no ophthalmic pathology except for a refractive error $< \pm 6.00 \mathrm{D}$ were included in the study. Subjects with facial malformation, orbital deformity, Graves's ophthalmopathy, orbital tumors, inflammation, orbital abnormalities, craniofacial abnormalities and people who had undergone any refractive surgeries were excluded from the study.

Approval of the study and verbal informed consent were obtained from the research ethics committee and the authorities concerned from the Lotus Eye Care Hospital and Institute administration, and its conduct followed the tenets of the Declaration of Helsinki. Informed oral consent was obtained from the study subjects who were above 18 years. For minors below 18 years of age the parent or legal guardian of the subjects provided the required verbal informed consent.

Luedde exophthalmometer was used to measure the extent of the ocular protrusion. All the absolute ocular protrusion measurements were taken with the same Luedde exophthalmometer, from the lateral orbital rim to the apex of the cornea in primary gaze. Ocular protrusion of both right and left eye was measured to the nearest $1 \mathrm{~mm}$. All the ocular protrusion values were measured by a single investigator and a single device in order to avoid variation between investigators and devices. Relative ocular protrusion was reported as the difference between the absolute ocular protrusion values of the right and left eye of the same individual. Refractive status is defined based on the subjective refraction values of the subjects. Subjects with subjective refraction values within $\pm 0.50 \mathrm{D}$ of spherical equivalent are defined as emmetropic, subjects with subjective refraction values greater than or equivalent to $-0.75 \mathrm{D}$ of spherical equivalent are defined as myopic and subjects with subjective refraction values greater than or equivalent to $+0.75 \mathrm{D}$ are defined as hyperopic.

To see the effect of age on ocular protrusion, subjects' ages were grouped as decades, and right eye absolute ocular protrusion data were used to compare the mean absolute ocular protrusion values among the groups. All the data were entered in Microsoft Excel and exported to SPSS (Version 25) before analyzing the data. One-way analysis of variance (one-way ANOVA) was used to compare the mean absolute ocular protrusion values among the different age groups and also to compare the mean ocular protrusion values among three refractive error groups. Further, Bonferroni post hoc correction was used to compare the mean differences in ocular protrusion within the groups. Independent $t$-test was used to compare the mean age and ocular protrusion values among the male and female subjects. Pearson correlation coefficient was used to report the relation between right and left eye absolute ocular protrusion values and also to see the relation between the magnitude of refractive error on absolute ocular protrusion. 
Table I Descriptive Data of Absolute and Relative Ocular Protrusion and Refractive Error Values in South Indian Population

\begin{tabular}{|c|c|c|c|c|c|c|c|}
\hline Age & $\begin{array}{c}\text { Mean Age } \pm \\
\text { Std. Dev } \\
\text { (Years) }\end{array}$ & $\begin{array}{c}\text { No. of } \\
\text { Subjects }\end{array}$ & $\begin{array}{c}\text { Mean Absolute } \\
\text { Ocular Protrusion } \\
\text { × Std. Dev }\end{array}$ & $95 \% \mathrm{Cl}$ & $\begin{array}{l}\text { Range of Absolute } \\
\text { Ocular Protrusion } \\
\qquad(\mathrm{mm})\end{array}$ & $\begin{array}{l}\text { Mean } \pm \text { Std. Dev } \\
\text { Refractive Error } \\
\text { (DSE) }\end{array}$ & $\begin{array}{c}\text { Mean } \\
\text { Relative } \\
\text { Ocular } \\
\text { Protrusion }\end{array}$ \\
\hline $1-10$ & $8.31 \pm 1.27$ & 93 & $\begin{array}{l}12.73 \pm 1.21(O D) \\
12.30 \pm 1.10(O S)\end{array}$ & $\begin{array}{l}12.48-12.98 \\
12.07-12.53\end{array}$ & $\begin{array}{l}11-17 \\
10-16\end{array}$ & $\begin{array}{l}-0.31 \pm 0.93(\mathrm{OD}) \\
-0.39 \pm 1.05(\mathrm{OS})\end{array}$ & $0.58 \pm 0.50$ \\
\hline $1 \mathrm{I}-20$ & $13.69 \pm 2.80$ & 55 & $\begin{array}{l}14.8 \pm 1.25(\mathrm{OD}) \\
14.40 \pm \mathrm{I} .33(\mathrm{OS})\end{array}$ & $\begin{array}{l}14.46-15.14 \\
14.04-14.76\end{array}$ & $\begin{array}{l}12-19 \\
12-18\end{array}$ & $\begin{array}{l}-0.42 \pm 1.29(\mathrm{OD}) \\
-0.37 \pm 1.05(\mathrm{OS})\end{array}$ & $0.51 \pm 0.50$ \\
\hline $21-30$ & $25.35 \pm 2.80$ & 71 & $\begin{array}{c}15.79 \pm 1.31(\mathrm{OD}) \\
\mathrm{I} 5.54 \pm 1.4 \mathrm{I}(\mathrm{OS})\end{array}$ & $\begin{array}{l}15.48-16.10 \\
15.20-15.87\end{array}$ & $\begin{array}{l}12-18 \\
12-18\end{array}$ & $\begin{array}{l}-1.13 \pm 1.50(\mathrm{OD}) \\
-1.24 \pm 1.27(\mathrm{OS})\end{array}$ & $0.54 \pm 0.51$ \\
\hline $31-40$ & $35.35 \pm 2.73$ & 49 & $\begin{array}{c}15.77 \pm 1.36(\mathrm{OD}) \\
\mathrm{I} 5.43 \pm \mathrm{I} .35(\mathrm{OS})\end{array}$ & $\begin{array}{l}15.39-16.17 \\
15.04-15.82\end{array}$ & $\begin{array}{l}14-19 \\
13-19\end{array}$ & $\begin{array}{l}-0.57 \pm 1.46(\mathrm{OD}) \\
-0.64 \pm 1.35(\mathrm{OS})\end{array}$ & $0.51 \pm 0.51$ \\
\hline $4 I-50$ & $44.74 \pm 2.63$ & 31 & $\begin{array}{l}15.87 \pm 1.28(\mathrm{OD}) \\
15.58 \pm 1.4 \mathrm{I}(\mathrm{OS})\end{array}$ & $\begin{array}{l}15.40-16.34 \\
15.06-16.10\end{array}$ & $\begin{array}{l}13-18 \\
13-18\end{array}$ & $\begin{array}{l}0.23 \pm 1.60(\mathrm{OD}) \\
0.02 \pm 1.58(\mathrm{OS})\end{array}$ & $0.48 \pm 0.51$ \\
\hline $5 I-60$ & $55.39 \pm 2.84$ & 46 & $\begin{array}{l}15.00 \pm 1.03(\mathrm{OD}) \\
14.59 \pm 1.02(\mathrm{OS})\end{array}$ & $\begin{array}{l}|4.69-15.3| \\
\mid 4.28-14.89\end{array}$ & $\begin{array}{l}13-17 \\
13-16\end{array}$ & $\begin{array}{l}0.10 \pm 1.80(\mathrm{OD}) \\
0.29 \pm 1.63(\mathrm{OS})\end{array}$ & $0.50 \pm 0.51$ \\
\hline $6 I-70$ & $64.76 \pm 2.60$ & 42 & $\begin{array}{l}14.36 \pm 0.88(\mathrm{OD}) \\
\mathrm{I} 4.07 \pm 0.95(\mathrm{OS})\end{array}$ & $\begin{array}{l}\mid 4.08-14.63 \\
\mid 3.78-14.37\end{array}$ & $\begin{array}{l}13-16 \\
12-16\end{array}$ & $\begin{array}{l}0.21 \pm 1.71(\mathrm{OD}) \\
0.23 \pm 1.45(\mathrm{OS})\end{array}$ & $0.52 \pm 0.51$ \\
\hline Total & $30.27 \pm 19.76$ & 387 & $\begin{array}{l}14.67 \pm 1.70(O D) \\
\mid 4.32 \pm 1.75(O S)\end{array}$ & $\begin{array}{l}14.50-14.84 \\
14.14-14.49\end{array}$ & $\begin{array}{l}11-19 \\
10-19\end{array}$ & $\begin{array}{l}-0.41 \pm 1.48(O D) \\
-0.34 \pm 1.35(O S)\end{array}$ & $0.53 \pm 0.50$ \\
\hline
\end{tabular}

Note: Bold numbers represent the mean data of total sample.

Abbreviations: Std. Dev, standard deviation; $\mathrm{Cl}$, confidence interval; DSE, diopters spherical equivalent.

\section{Results}

Descriptive data (Table 1) show that out of 387 subjects 190 were males (49.1\%) and 197 were females (50.9\%). Mean age of the subjects was $30.27 \pm 19.76$ years. Mean ages of male and female subjects were $28.56 \pm 19.63$ years and $31.91 \pm 19.80$ years, respectively. Independent $t$-test shows that the mean ages of male and female subjects were not statistically significantly different $(p=0.07)$. The mean ages of seven groups were $8.31 \pm 1.27$ years, $13.69 \pm 2.80$ years, $25.35 \pm 2.80$ years, $35.35 \pm 2.73$ years, $44.74 \pm 2.63$ years, $55.39 \pm 2.84$ and $64.76 \pm 2.60$ years, respectively.

\section{Age versus Absolute Ocular Protrusion}

Pearson correlation coefficient showed a very high correlation $(r=0.951)$ between the right and left absolute ocular protrusion values of individuals, which was statically significant $(p=<0.0001)$, hence we used right eye data to compare the means of the absolute ocular protrusion data in different age groups.

Box plots of mean absolute ocular protrusion of right eye for all the seven decades are presented in Figure 1. It is evident from Figure 1 that there is a significant increase in ocular protrusion values in first three decades, stabilising from third to fifth decade and a significant decrease from fifth decade to seventh decade. The mean right absolute ocular protrusion values from 1 st to 7 th decade were $12.73 \pm 1.21 \mathrm{~mm}, 14.8 \pm 1.25 \mathrm{~mm}, 15.79 \pm$ $1.31 \mathrm{~mm}, 15.77 \pm 1.36 \mathrm{~mm}, 15.87 \pm 1.28 \mathrm{~mm}, 15.00 \pm$ $1.03 \mathrm{~mm}$ and $14.36 \pm 0.88 \mathrm{~mm}$, respectively. The corresponding mean values of absolute ocular protrusion for right and left eye along with the $95 \%$ confidence interval are presented in Table 1. One-way analysis of variance (one-way ANOVA) shows that there was a significant difference in the ocular protrusion among the age groups ( $p<0.005$ ); however, further post hoc analysis using Bonferroni post hoc correction reveals that the mean absolute ocular protrusion was not significantly different between the third and fifth decade $(p>0.99)$. Similarly, the difference between the mean ocular protrusion in the second and sixth decade $(p>0.99)$ as well as between the second and seventh decade $(p>0.99)$ was not significant. However, the mean ocular protrusion in the first decade was significantly different from the others $(p<0.001)$.

The association between ocular protrusion and age shows a quadratic function $(y=11.32+0.25 \mathrm{x}-$ 


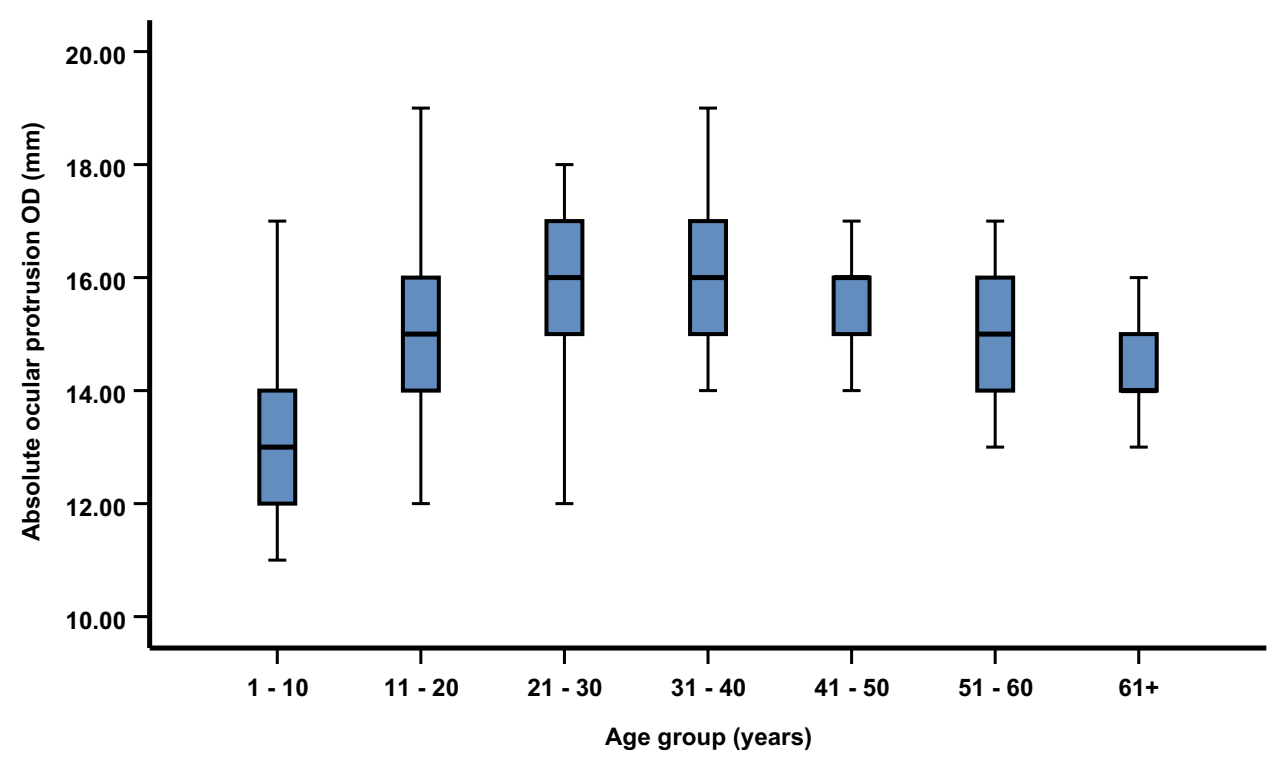

Figure I Box plots of mean right absolute ocular protrusion in different age groups. The thick solid line in the box shows the median of the ocular protrusion. The error bars represent 5 th percentile and 95 th percentile values.

$0.00313 \mathrm{x}^{2}$ ). The quadratic function presented in Figure 2 clearly shows that there is a steep increase in the ocular protrusion from childhood to the third decade, then the rate of increase in ocular protrusion slows down till the fifth decade and it falls steeply from the fifth decade.

\section{Gender versus Ocular Protrusion}

Among the 387 subjects, 197 (50.9\%) subjects were females and $190(49.1 \%)$ subjects were males. The mean right eye and left eye protrusion in females is $14.58 \pm 1.71 \mathrm{~mm}$ and $14.17 \pm 1.77 \mathrm{~mm}$, and in males is $14.76 \pm 1.68 \mathrm{~mm}$ and $14.46 \pm 1.71 \mathrm{~mm}$, respectively. Independent $t$-test shows that there is a significant difference in mean right absolute ocular protrusion values between male and female subjects $(p \leq 0.001)$.

\section{Refractive Status versus Ocular Protrusion}

To see the effect of refractive error on absolute ocular protrusion, all the subjects were divided into three groups

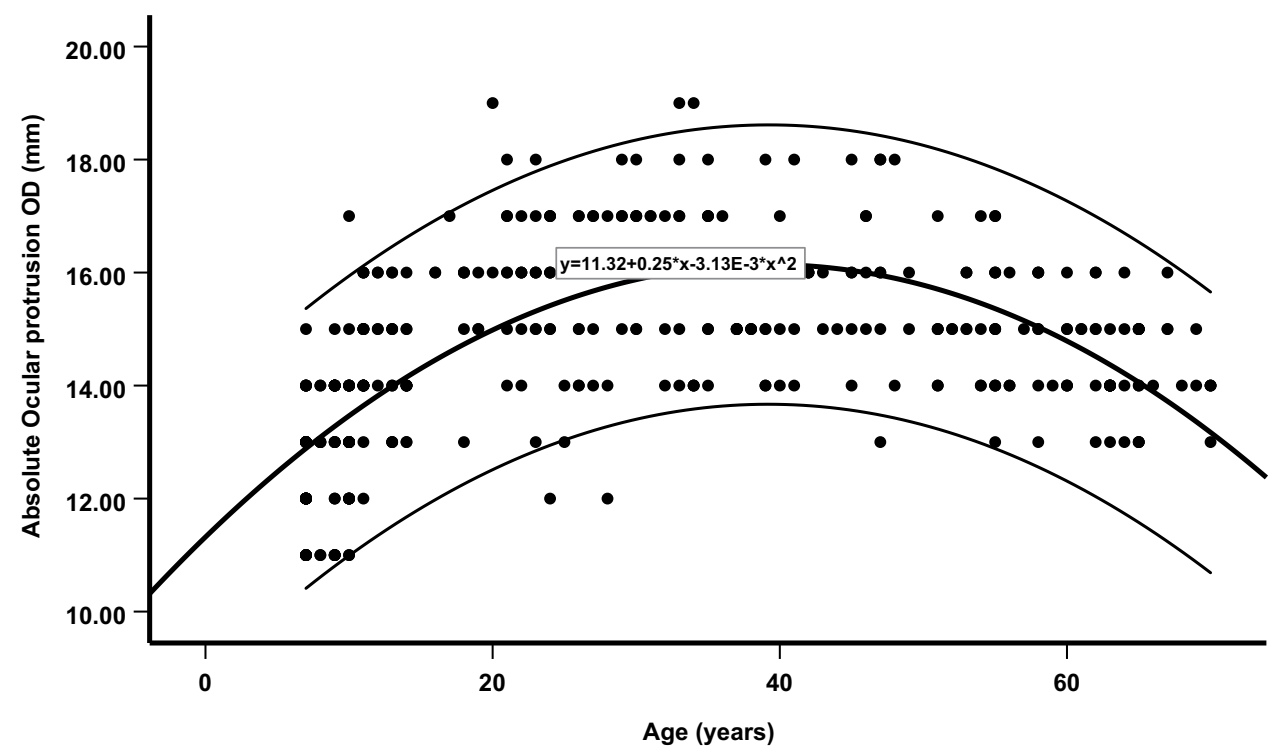

Figure 2 Quadratic function (thick curve, middle) is showing the absolute right eye (OD) absolute ocular protrusion values as a function of age. The equation shown in the box is the quadratic equations of the fit. Thin curves (above and below the thick curve) show $95 \%$ confidence intervals of individuals at a given age. 
Table 2 Descriptive Data of Right Eye Mean Refractive Error and Right Eye Mean Absolute Ocular Protrusion Values Among Myopic, Emmetropic and Hyperopic Subjects in South Indian Population

\begin{tabular}{|l|c|c|c|c|}
\hline $\begin{array}{l}\text { Type of Ref. } \\
\text { Error }\end{array}$ & $\begin{array}{c}\text { Number of Eyes } \\
\text { (OD) }\end{array}$ & $\begin{array}{c}\text { OD_Ref. Error } \pm \text { Std. Dev } \\
\text { (DSE) }\end{array}$ & $\begin{array}{c}\text { Mean Absolute Ocular Protrusion } \pm \text { Std. Dev } \\
(\mathbf{m m})\end{array}$ & p-value \\
\hline Myopia & 155 & $-1.83 \pm 0.92$ & $14.83 \pm 1.67$ & $14.49 \pm 1.78$ \\
Emmetropia & 153 & $-0.08 \pm 0.33$ & $14.68 \pm 1.54$ & 0.221 \\
Hyperopia & 79 & $1.61 \pm 0.65$ & \\
\hline
\end{tabular}

Abbreviations: Ref. error, refractive error; Std. Dev, standard deviation; DSE, diopters spherical equivalent.

as emmetropic, myopic and hypermetropic, depending upon the refractive error. Out of 774 eyes of 387 subjects, $41 \%$ of eyes were emmetropic, $40.5 \%$ of eyes were myopic and $18.5 \%$ of eyes were hyperopic. Right eye data were used to analyze the results. The mean right eye refractive error and right absolute ocular protrusion values among the three groups are presented in Table 2. Mean right absolute ocular protrusion of emmetropic subjects is $14.49 \pm 1.78 \mathrm{~mm}$, of myopic subjects $14.83 \pm 1.67 \mathrm{~mm}$ and in hyperopic subjects $14.68 \pm 1.54 \mathrm{~mm}$, respectively. One-way ANOVA shows that there is no significant difference $(p=0.22)$ in the mean right ocular protrusion values among three types of refractive groups. In order to find the relation between magnitude of the refractive error and absolute ocular protrusion among myopes and hyperopes, Pearson correlation analysis was performed. The scatter plot presented in Figure 3A shows the correlation between magnitude of myopia and absolute ocular protrusion; the scatter plot presented in Figure 3B shows the correlation between magnitude of hyperopia and absolute ocular protrusion. A weak positive correlation (Pearson correlation coefficient $r=0.54, p<0.001$ ) was noted between the magnitude of myopia and absolute ocular protrusion, and very weak positive correlation $(r=0.22, p=$ 0.04 ) was noted between the magnitude of hyperopia and absolute ocular protrusion.

\section{Relative Ocular Protrusion}

Mean relative ocular protrusion of the total subjects is $0.53 \pm 0.50 \mathrm{~mm}$. Mean relative ocular protrusion of all seven groups ranged from $0.48 \mathrm{~mm}$ to $0.61 \mathrm{~mm}$. Corresponding mean relative ocular protrusion values of each decade are presented in Table 1 . There was no significant difference $(p=0.99)$ in the mean relative ocular protrusion values among different age groups. A total of $51 \%$ of the subjects showed a relative ocular protrusion of $1 \mathrm{~mm}$, and $49 \%$ subjects showed no difference between the absolute ocular protrusion values of the eyes.

\section{Discussion}

Results of the present study show that the mean ocular protrusion measured from 387 normal individuals of south India from all age groups is $14.67 \pm 1.70 \mathrm{~mm}$. The mean ocular protrusion measured from south Indian population in this study is less than that of white American, African American, ${ }^{8,10,11}$ Chinese, ${ }^{12,13}$ white European ${ }^{14}$ and Mexican ${ }^{15}$ populations, more than in the Turkish ${ }^{3,4}$ population and similar to Iranian ${ }^{9}$ and north Indian ${ }^{16,17}$ populations. The discrepancies in the ocular protrusion among the different races could be due to the differences in ocular anatomy and facial structure.

Apart from race, other features like gender, age and refractive status may have an effect on variation in normal ocular protrusion values. Regarding the gender, some studies have shown a significant difference in ocular protrusion between the males and females, especially in white and black American populations. ${ }^{10}$ The present study has shown a significant difference in ocular protrusion between the two genders, where males have more mean ocular protrusion than females.

Regarding the relation between ocular protrusion and age, previous studies have reported a general trend that ocular protrusion increases in the first two decades of life because of facial modeling and/or increase in orbital soft tissue volume, and no change or decrease from the third to the sixth decade of life and then a decrease in the seventh decade onwards. ${ }^{9,14,16}$ The present study has also shown a similar trend with is a steep increase in the ocular protrusion till the third decade of life, no change till fifth decade and then a steep fall from fifth to seventh decade. Adding to this, the present study also used a quadratic function to describe the relationship between age and ocular proptosis. The quadratic function presented in this study has provided the information about calculating the ocular protrusion at a given age and would be very helpful for clinicians in interpreting the normal ocular protrusion values in the south Indian population. 


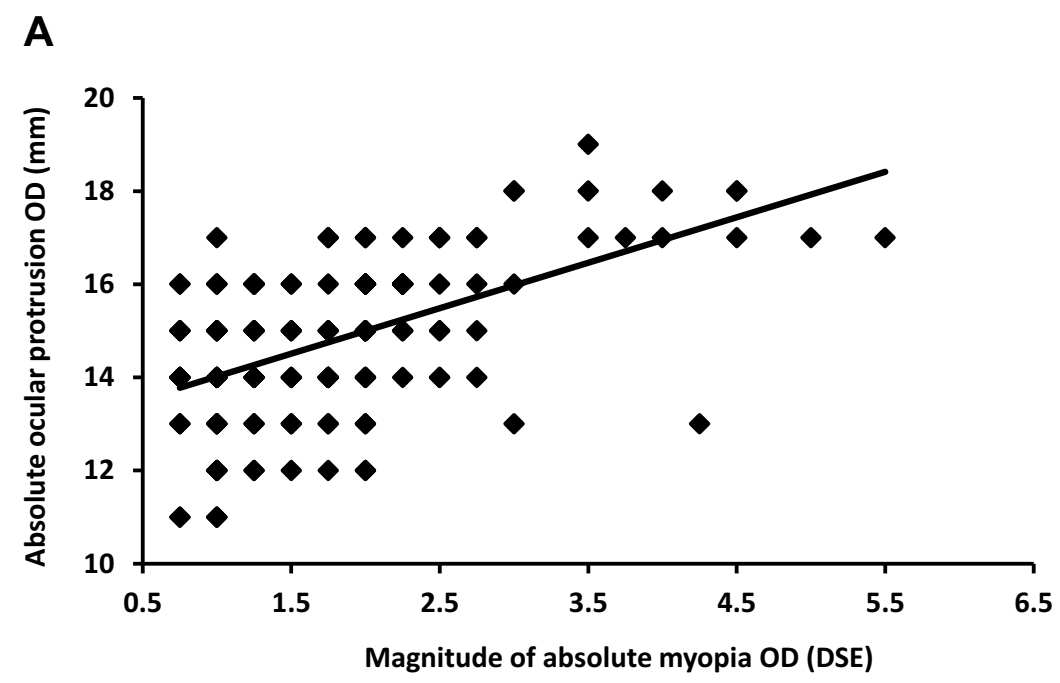

B

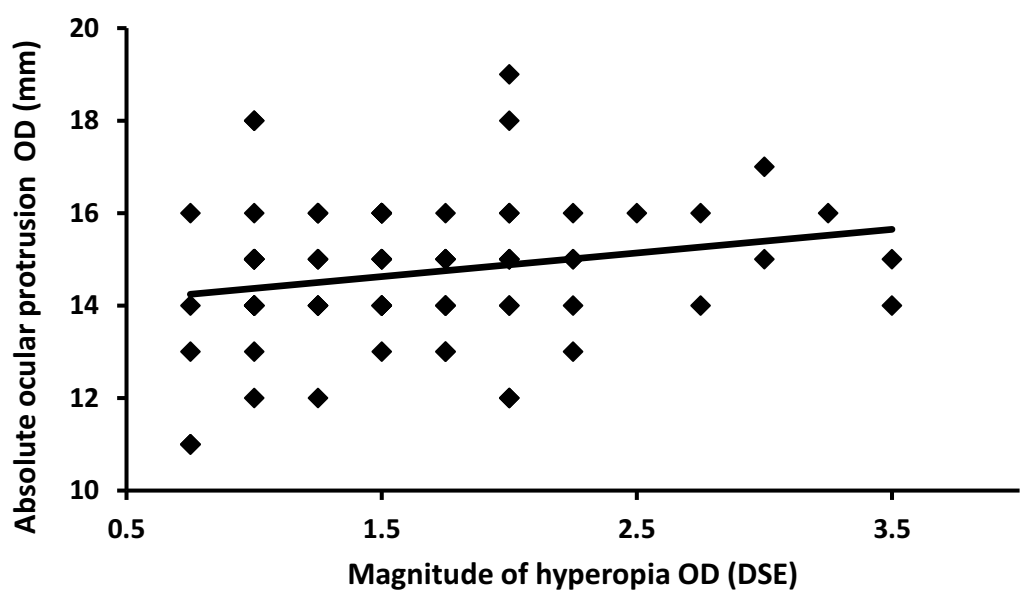

Figure 3 Scatter plots showing the correlation between (A) magnitude of absolute myopia and absolute ocular protrusion; (B) magnitude of hyperopia and absolute ocular protrusion. Note that DSE on X-axis of both plots stands for diopter spherical equivalent.

With respect to refractive error up to \pm 6.00 diopters, the present study has not shown any significant differences in mean absolute ocular protrusion values among the myopic and hyperopic and emmetropic groups. In addition to this, Pearson correlation coefficient shows weak and very weak correlation between absolute ocular protrusion values and magnitude of myopia and hyperopia, respectively. From this finding, we may predict that mild to moderate myopia or hyperopia (up to $\pm 6.00 \mathrm{D}$ ) has no role to play on absolute ocular protrusion values. This finding is in concurrence with many previously reported studies. ${ }^{4,10,13,14}$

There are different reports concerning relative ocular protrusion. The common conclusion from these studies is that there is an asymmetry in ocular protrusion between right and left eye in few subjects up to $2 \mathrm{~mm} .{ }^{4,9,10,18,19}$
Kashkouli et al found that right ocular protrusion values were significantly greater than left ocular protrusion. ${ }^{9} \mathrm{Wu}$ et al also found that a minority of their study subjects showed relative ocular protrusion of greater than $2 \mathrm{~mm}^{12}$ The present study also revealed that $51 \%$ of subjects had relative ocular protrusion of $1 \mathrm{~mm}$. Additionally, the mean difference in absolute ocular protrusion between both eyes was statistically significant. However, a high correlation was found between the right and left eye of individual subjects. It has been suggested that, in clinical practice, relative ocular protrusion of $2 \mathrm{~mm}$ or less is not considered as clinically significant. None of our study subjects had a relative ocular protrusion of greater than $2 \mathrm{~mm}$. This finding may suggest that the statistically significant difference in mean absolute ocular 
protrusion values between both eyes presented in this study was not clinically significant.

\section{Conclusion}

Normal absolute ocular protrusion values in south Indian subjects are influenced by age, and it significantly increases from first to third decade and decreases from fifth decade. Age-matched normative data presented in this study would be helpful in early diagnosis and management of patients with orbital and endocrine diseases that cause an increase in ocular protrusion. Mild and moderate amounts of myopia or hyperopia (up to $\pm 6.00 \mathrm{D}$ ) are not a concern when reporting normal absolute ocular protrusion values. Gender should be taken into consideration while measuring the ocular protrusion.

\section{Acknowledgments}

Authors of the study would like to acknowledge Mrs. Jeslin Joseph from Lotus Eye Care Hospital for her valuable contribution in analysis of results of the study.

\section{Disclosure}

The authors report no conflicts of interest in this work.

\section{References}

1. Duke-Elder WS. The ocular adnexa. In: Duke-Elder WS, editor. System of Ophthalmology. Vol. 13. Mosby; 1974.

2. Chan W, Simon NM, Tissa S, et al. Exopthalmometric values and their biometric correlates: the Kandy Eye Study. Clin Exp Ophthalmol. 2009;37(5):496-502. doi:10.1111/j.1442-9071.2009.02087.x

3. Bilen H, Gullulu G, Akcay G. Exophthalmometric values in a normal Turkish population living in northeast part of Turkey. Thyroid. 2007;17 (6):525-528. doi:10.1089/thy.2006.0279

4. Beden U, Ozarslan Y, Ozturk HE, Sonmez B, Erkan D, Oge I. Exophthalmometry values of Turkish adult population and the effect of age, sex, refractive status, and Hertel base values on Hertel readings. Eur J Ophthalmol. 2008;18(2):165-171. doi:10.1177/112067 210801800201

5. Segni M, Bartley G, Garrity JA, Bergstralh EJ, Gorman CA. Comparability of proptosis measurements by different techniques. Am J Ophthalmol. 2002;133(6):813-818. doi:10.1016/s0002-9394(02) 01429-0
6. Onofrey BE. Ocular Therapeutics Handbook: A Clinical Manual. 3rd ed. Onofrey BE, editor. Philadelphia:Wolters Kluwer, Lipponcott Williams; 2011.

7. Chang AA, Bank A, Francis IC, Kappagoda MB. Clinical exophthalmometry: a comparative study of the Lued And Hertel exophthalmometer. Aust N Z J Psychiatry. 1995;23(4):315-318. doi:10.1111/j.1442-9071.1995.tb00182.x

8. Cole HP, Couvillion JT, Fink AJ, Haik BG, Kastl PR. Exophthalmometry: a comparative study of the Naugle and Hertel instruments. Ophthal Plast Reconstr Surg. 1997;13(3):189-194. doi:10.1097/00002341-199709000-00005

9. Kashkouli MB, Nojomi M, Paravaresh MM, Sanjari MS, Modarres M, Nooranj MM. Normal values of hertel exophthalmometry in children, teenagers, and adults from Tehran, Iran. Opt Vis Sci. 2008;85(10):1012-1017. doi:10.1097/OPX.0b013e3181890dc7

10. Migliori ME, Gladstone GJ. Determination of the normal range of exophthalmometric values for black and white adults. $\mathrm{Am}$ J Ophthalmol. 1984;98(4):438-442. doi:10.1016/0002-9394(84)90 127-2

11. Dunsky IL. Normative data for Hertel's exophthalmometry in a normal adult black population. Optom Vis Sci. 1992;69(7):562. doi:10.1097/00006324-199207000-00009

12. Wu D, Xin L, Wu D, et al. Normal values of Hertel exophthalmometry in a Chinese Han population from Shenyang, Northeast China. Sci Rep. 2015;5(1):8526. doi:10.1038/srep08526

13. Quant JR, Woo GC. Normal values of eye position in the Chinese population of Hong Kong. Optom Vis Sci. 1992;69(2):152-158. doi:10.1097/00006324-199202000-00009

14. Fledilius HC, Stubgaard M. Changes in ey position during growth with an adult life. Acta Ophthalmol. 1986;64(5):481-486. doi:10.11 11/j.1755-3768.1986.tb06958.x

15. Bolonos GMF, Rezresinas FF, Rodriguez Garcia M, Gonzalez Ortiz M. Exophthalmometry in Mexican adults. Rev Invest Clin. 1999;51(6):341-343.

16. Nath K, Gogi R, Rao GS, Krishna G, Zaidi N. Normal exophthalmometry. Indian J Ophthalmol. 1977;25(3):47-52. doi:10. 1016/0065-2571(75)90028-x

17. Sodhi PK, Gupta VP, Pandey RM. Exophthalmometric values in a normal Indian population. Orbit. 2001;20(1):1-9. doi:10.1076/ orbi.20.1.1.2647

18. Mourits MP, Lombardo SH, van der Slujis FA, Flenton S. Reliability of exophthalmos measurement and the exophthalmometry value distribution in a healthy Dutch population and in Graves'patients. An exploratory study. Orbit. 2004;23(3):147-151. doi:10.1080/01676 830490504089

19. Kim IT, Choi BJ. Normal range of exophthalmos values on orbit computerized tomography in Koreans. Ophthalmologica. 2001;215 (3):156-162. doi:10.1159/000050850
Clinical Ophthalmology

\section{Publish your work in this journal}

Clinical Ophthalmology is an international, peer-reviewed journal covering all subspecialties within ophthalmology. Key topics include: Optometry; Visual science; Pharmacology and drug therapy in eye diseases; Basic Sciences; Primary and Secondary eye care; Patient Safety and Quality of Care Improvements. This journal is indexed on PubMed
Dovepress

Central and CAS, and is the official journal of The Society of Clinical Ophthalmology (SCO). The manuscript management system is completely online and includes a very quick and fair peer-review system, which is all easy to use. Visit http://www.dovepress.com/ testimonials.php to read real quotes from published authors. 